\title{
A Computer Model of Upward Flame Spread on Vertical Surfaces
}

\author{
CRAIG L. BEYLER, SEAN P. HUNT and NAEEM IQBAL \\ Hughes Associates Inc. \\ 3610 Commerce Drive, Suite 817 \\ Baltimore, Maryland, 21227, USA \\ FREDERICK W. WILLIAMS \\ Naval Research Laboratory \\ Washington, DC 20375, USA
}

\begin{abstract}
A model which describes the physical processes of upward flame spread and fire growth on wall materials has been developed and implemented as a computer program. The computerbased flame spread model simulates the fire growth along a vertical combustible wall. The vertical wall material may be heated by an imposed external heat flux and is ignited at its bottom edge with a flame from a line burner of user specified strength. The model predicts the flame spread rate, the heat release rate of the fire, the flame height, the net heat flux to the wall surface, and the time varying surface temperature. The model uses inputs developed from cone calorimeter data. The results from the model compare favorably to upward flame spread experimental results for PMMA, plywood, and vinyl-ester/glass composite found in the literature.
\end{abstract}

KEYWORDS: $\quad$ Vertical flame spread, wall fire, computer program, material properties, small- and full-scale fire test, prediction, and validation.

\section{INTRODUCTION}

In this paper, a vertical flame spread model is developed and validated against literature data. This work is a part of U.S. Navy Passive Fire Protection (PFP) Program and designed to provide a technique for specifying the performance required for the U.S. Navy material applications in terms of small-scale tests. The PFP program will result in known fire performance of material applications and will allow manufacturers/developers to provide costeffective materials with the required performance. 
The upward flame spread model on vertical surfaces is the first part of the modeling effort designed to develop a general modeling framework, which will assess performance of materials in Navy fire scenarios from small-scale test data. This model is formulated on the basis of a review of the fire dynamics literature relevant to fire growth presented by Williams and Beyler [1].

A computer model has been developed which calculates the flame spread on a vertical wall subject to a line ignition source. Flame spread is calculated using sub-models derived from the literature and inputs determined from cone calorimeter tests. The model is formulated based on existing sub-models of (1) ignition, (2) material heating, pyrolysis, and burning rate, (3) flame spread, and (4) flame and surface heat transfer. The details for each component of the analysis will be described in the following sections.

\section{THEORY AND DESCRIPTION OF THE MODEL}

The computer model calculates the flame spread on a vertical surface by breaking up the surface into a large number of elements. The conditions of each element are independently computed. The centroid of an element is assumed to be representative of the entire element. There are a number of global conditions that are calculated by summing the contributions from each element: the heat release rate, the height of the pyrolysis, the flame height along the wall, and the height of burnout front along the wall.

Each element is in one of four states: (1) preheating (above the flame), (2) heating (exposed to the flame), (3) burning, and (4) consumed. The model keeps track of these conditions for each element, and the model stops when either the user entered simulation time is reached, the fuel is entirely consumed, or the flame propagation ceases.

\section{Wall Flame Heights and Heat Fluxes to the Surface}

In the present model, the wall can be heated by three sources: (1) an imposed external heat flux, (2) a line fire placed against the base of the wall (the ignitor), and (3) the wall flame itself. It has been shown that the heat flux to the wall from line fires against the wall and the wall itself can be correlated in the same manner [2].

Correlation for the heat fluxes from the methane line burner to an adjacent wall along with similar results for fire involving liquid fuels saturated on the lower portion of wall has been developed from data presented by Quintiere and Cleary [2]. This correlation can be expressed as 


$$
\begin{array}{ll}
\dot{q}^{\prime \prime}(y)=20 \frac{\mathrm{kW}}{\mathrm{m}^{2}} & \frac{y}{y_{f}}<0.34 \\
\dot{q}^{\prime \prime}(y)=6.23 y^{-1.07} \frac{\mathrm{kW}}{\mathrm{m}^{2}} & 0.34 \leq \frac{y}{y_{f}}<0.7 \\
\dot{q}^{\prime \prime}(y)=3.59 y^{-2.32} \frac{\mathrm{kW}}{\mathrm{m}^{2}} & \frac{y}{y_{f}}>0.7
\end{array}
$$

where $\dot{q}^{\prime \prime}(y)$ is the incident heat flux from the line burner to the wall surface $\left(\mathrm{kW} / \mathrm{m}^{2}\right), y$ is the height above the floor $(\mathrm{m})$, and $y_{f}$ is the flame height $(\mathrm{m})$. This correlation is useful for representing methane burner ignitor and commonly used liquid ignitor fuels. An alternative approach available in the model is the use of one of the wall fire heat flux correlations listed later in this section. These correlations are based on more luminous fuels which are typical of wall flames and non-methane line burners. The result of using the wall heat flux correlations is a more rapid ignition; however, the fire growth will be similar.

Equation (1) requires the determination of the flame height. There are several flame height correlations available for the line fire against a wall and wall fires [3,4]. Each of these takes the form:

$$
\begin{aligned}
& y_{f}=C_{f} \dot{Q}^{\frac{2}{3}} \quad \text { for } \quad \frac{y_{f}}{y_{p}} \geq R \\
& y_{f}=R y_{p} \quad \text { for } \quad \frac{C_{f} \dot{Q}^{\prime \frac{2}{3}}}{y_{p}}<R
\end{aligned}
$$

where $y_{f}$ is the wall flame height (m), $y_{p}$ is the pyrolysis front $(\mathrm{m}), \dot{Q}^{\prime}$ is the heat release rate per unit length of the line burner $(\mathrm{kW} / \mathrm{m}), C_{f}$ is a constant $\left(\mathrm{m}^{5 / 3} / \mathrm{kW}^{2 / 3}\right)$, and $R$ is the minimum ratio of the flame height to the pyrolysis height.

Delichatsios [3] recommends $C_{f}=0.052 \mathrm{~m}^{5 / 3} / \mathrm{kW}^{2 / 3}$, and Tu and Quintiere [4] recommend $C_{f}=0.0666 \mathrm{~m}^{5 / 3} / \mathrm{kW}^{2 / 3}$. The second part of Equation (2) is applicable to wall fires with low heat release rates per unit area where the first part of Equation (2) would erroneously indicate that the flame height is less than the pyrolysis height. Based on the work on Tewarson [5], $R$, the minimum ratio of the flame height to the pyrolysis height, is in the range of 1.0-1.1.

Upon the ignition of the wall, the luminosity of the flame may increase over that typical of a methane ignitor flame. The model allows the use of a different heat flux correlation after ignition of the wall. The incident heat flux from wall flames to the surface has been experimentally determined for a number of materials. Heat fluxes distributions are prescribed based on prior work available in the literature which has been summarized by Quintiere [6]. Based on flame heat flux data presented by Quintiere [6], different heat flux correlations have been developed for line diffusion flames to a vertical wall. Equations (3) and (4) are representative of the available flame heat flux data. 


$$
\begin{array}{ll}
\dot{q}_{e}^{\prime \prime}(y)=5.39\left(\frac{\left(y-y_{b}\right)}{\left(y_{f}-y_{b}\right)}\right)^{-2.3} & \frac{\left(y-y_{b}\right)}{\left(y_{f}-y_{b}\right)} \geq 0.53 \\
\dot{q}_{e}(y)=23 \frac{\mathrm{kW}}{\mathrm{m}^{2}} & \frac{\left(y-y_{b}\right)}{\left(y_{f}-y_{b}\right)}<0.53
\end{array}
$$

where $\dot{q}_{e}^{\prime \prime}(y)$ is the incident heat flux from the flame to the surface $\left(\mathrm{kW} / \mathrm{m}^{2}\right)$, y is the height above the base of the burning wall (m), $y_{b}$ is the height of the burnout front (m), and $y_{f}$ is the height of the flame tip above the base of the burning wall (m).

Additional correlations which bound the available data are also available in the program. The selection among these correlations will depend on the flame luminosity and the level of conservatism required.

\section{Surface Heating and Ignition}

Prior to ignition, the wall surface is assumed to be a semi-infinite one-dimensional slab with a time dependent surface heat flux determined from the wall flame and external sources as described above. The conduction model used in this computer model is an approximate solution to the semi-infinite slab problem using an assumed cubic temperature profile and an integral solution [7]. This method was selected based on its excellent predictive performance and computational efficiency.

Applying boundary conditions to the semi-infinite slab problem, the resulting temperature profile becomes:

$$
T_{s}(y, t)=T_{o}+\frac{\dot{q}^{\prime \prime}{ }_{n e t} \delta}{3 k}\left[1-\frac{z}{\delta}\right]^{3}
$$

where $T_{o}$ is the initial surface temperature $\left({ }^{\circ} \mathrm{C}\right.$ or $\left.\mathrm{K}\right), \dot{q}^{\prime \prime}{ }_{n e t}$ is the time dependent net heat flux $\left(\mathrm{kW} / \mathrm{m}^{2}\right), \delta$ is the thermal penetration depth $(\mathrm{m}), z$ is the depth into the wall surface $(\mathrm{m})$, and $k$ is the thermal conductivity $(\mathrm{kW} / \mathrm{m}-\mathrm{K})$. The surface temperature, $\mathrm{T}_{\mathrm{s}}$, at any time is then given by the following differential equations:

$$
\begin{aligned}
& 2\left(T_{s}(y, t)-T_{o}\right) \frac{d T_{s}(y, t)}{d t}-\frac{\left[T_{s}(y, t)-T_{o}\right]^{2}}{\dot{q}_{n e t}^{\prime \prime}(y, t)} \frac{d \dot{q}_{n e t}^{\prime \prime}(y, t)}{d t}=\frac{4 \dot{q}_{n e t}^{\prime \prime}(y, t)}{3 k \rho c} \\
& \frac{d \dot{q}_{n e t}^{\prime \prime}(y, t)}{d t}=-4 T_{s}(y, t)^{3} \frac{d \dot{q}_{n e t}^{\prime \prime}(y, t)^{3}}{d t}
\end{aligned}
$$


Equations (6) and (7) are solved in the flame spread model using a fourth order Runge-Kutta method for each time step. This provides a very efficient method for predicting the heating of the surface to the ignition temperature. The thermal inertia, $k \rho c$, and the ignition temperature are determined from ignition experiments in the cone calorimeter.

\section{Heat Release Rate}

Once an element has reached the ignition temperature, it is allowed to pyrolyze, burn, and contribute energy to the wall fire. The heat release rate of the wall is determined by summing the heat release rates of each burning element.

$$
\dot{Q}=\Delta H_{c} \sum_{i=1}^{n} m_{i}^{\prime \prime}(y, t) A_{i}(y)
$$

where $n$ is the number of elements which are burning at time $t(\mathrm{sec}), \Delta H_{c}$ is the heat of combustion of the wall material $(\mathrm{kJ} / \mathrm{kg}), m_{i}{ }^{\prime \prime}(\mathrm{y}, \mathrm{t})$ is the spatially and temporally varying mass loss rate per unit area $\left(\mathrm{kg} / \mathrm{m}^{2}\right)$, and $A_{i}(y)$ is the area of the element under consideration $\left(\mathrm{m}^{2}\right)$. Both elemental area and the mass loss rate are allowed to vary from element to element although there is currently no convenient way to specify elements of variable size. The mass loss rate for each element is given by

$$
\dot{m}^{\prime \prime}(y, t)=\frac{\dot{q}_{n e t}^{\prime \prime}(y, t)}{\Delta h_{g}}
$$

where $\Delta h_{g}$ is the heat of gasification $(\mathrm{kJ} / \mathrm{kg})$ as determined from the cone calorimeter. The net energy $\left(\dot{q}_{\text {net }}\right.$ ") absorbed by the each burning element can be calculated from the following equation:

$$
\dot{q}_{n e t}^{\prime \prime}(y, t)=\dot{q}_{i m p}^{\prime \prime}+\dot{q}_{e}^{\prime \prime}(y, t)-\sigma \in\left[T_{s}(y, t)^{4}-T_{o}^{4}\right]
$$

where $\dot{q}_{i m p}$ "is the imposed heat flux (a constant and uniform heat flux used to heated the material surface, $\dot{q}_{e}$ "is the incident heat flux from the flame to the surface $\left(\mathrm{kW} / \mathrm{m}^{2}\right), T_{s}$ is the surface pyrolysis temperature $(\mathrm{K}), T_{o}$ is the ambient temperature $(\mathrm{K}), \epsilon$ is the emissivity, and $\sigma$ is the Stefan-Boltzmann constant $\left(5.668 \times 10^{-11} \mathrm{~kW} / \mathrm{m}^{2}-\mathrm{K}^{4}\right)$.

\section{Material Property Data}

The material properties required by the model are determined using the cone calorimeter ASTM standard test method E-1354. These properties are (1) ignition temperature, $T_{i g},(\mathrm{~K})$, (2) thermal inertia, $k \rho c,\left(\mathrm{~kW} / \mathrm{m}^{2}-\mathrm{K}\right)^{2} \mathrm{sec}$, (3) effective heat of gasification, $\Delta h_{g}(\mathrm{~kJ} / \mathrm{kg})$, and (4) heat of combustion, $\Delta H_{c}(\mathrm{~kJ} / \mathrm{kg})$. The sources of the data and detailed method for determining these properties are presented in Williams et al. [8]. 


\section{Numerical Simulation Computer Program}

The upward flame spread model is written in LAHEY FORTRAN 90. The computer program calculates flame spread at each element of the vertical surface, elements can be in preheating above the flame, in preheating behind the flame, ignited, burned out, or inert (void). An element is defined as a small sub-area where the conditions are uniform across the surface. Thus, smaller the element will result in greater accuracy.

The main program structure is divided into a main driver responsible for calling the various subroutines. There are subroutines for reading data, calculating results, and reporting the results to a file or printer. The main program calls the subprograms or subroutines that read the data and calculate the surface temperature at each element, heat release rate, and flame height. At each time step, subroutines update the status of each element and calculate the current heat release rate and flame height.

Five hundred elements were used to produce each of the model comparison results. In all cases, a time step of 1 second has been shown to produce accurate solutions.

\section{RESULTS OF THE MODEL}

The model results were compared with small- and full-scale tests to evaluate the capabilities of the computer program in predicting vertical spread. Heat release rates, surface temperatures, and flame heights were compared with data available in the literature. No tests were found that described in adequate detail all of the potential characteristics for comparison. In addition, the test conditions were not adequately described in terms of the ignition temperature, material properties, and heat flux conditions. Comparisons were made using values or data from other literature sources.

Validation of the numerical solution for upward flame spread was made by comparing with full-scale experimental results using material properties from small-scale data available in the literature. Full-scale data were available for vertical flame spread on polymethylmethacrylate (PMMA), plywood, and vinyl-ester/glass composite. The present numerical solution was compared to the experimental measurement of flame spread over a vertical PMMA surface by $\mathrm{Wu}$ et al. [9], the experimental measurements of flame spread over a vertical surface of plywood with externally applied radiation flux by Delichatsios et al. [10], and vertical measurements on vinyl-ester/glass composite panel by Ohlemiller and Cleary [11]. The ignition and flame spread properties and dimensions (input for model) are based on the small-scale test data available in the literature and in Reference 8.

\section{Comparison of Predicted Results with Experimental Results for Non-Charring Polymethylmethacrylate (PMMA)}

Wu et al. [9] measured heat release rates for small-scale and full-scale PMMA wall fires. In the experiments, a vertical PMMA slab measuring $0.90 \mathrm{~m}$ high, $0.2 \mathrm{~m}$ wide, and $25 \mathrm{~mm}$ thick was ignited at the bottom of the panel. The full-scale flame spread experiments were carried out with a $25 \mathrm{~mm}$ thick PMMA slab, $0.58 \mathrm{~m}$ wide $\times 5 \mathrm{~m}$ high. The ignition source was $35 \mathrm{~mL}$ 
of heptane in a copper dish at the bottom of the wall. This was simulated in the model as a $1 \mathrm{~kW} / \mathrm{m}$ line fire source.

Figures 1 and 2 compare the predicted heat release rate and measured heat release rate for $0.90 \mathrm{~m} \times 0.20 \mathrm{~m}$ and $5.0 \mathrm{~m} \times 0.58 \mathrm{~m}$ vertical PMMA surfaces. The solid line is the model prediction while dash line is the experimental data of Wu et al. [9]. Due to the sensitivity of the computer model to the heat flux and flame height correlations, several simulations of the test were performed in order to determine the optimum combination. The results in Figure 1 and 2 show reasonable agreement with experimental data using the flame height correlation given by $\mathrm{y}_{\mathrm{f}}=0.052 \dot{\mathrm{Q}}^{2 / 3 \prime}[3]$. Since exact value of flame heat flux after ignition were not described in the test conducted by Wu et al. [9] after several runs, peak flame heat fluxes of $21 \mathrm{~kW} / \mathrm{m}^{2}$ and $36 \mathrm{~kW} / \mathrm{m}^{2}$ for the small- and large-scale tests, respectively, were found to yield the best agreement.

\section{Comparison of Predicted Results with Experimental Results for Plywood}

Delichatsios et al. [10] have conducted theoretical and experimental analysis of upward fire spread along $2.4 \mathrm{~m}$ high, $0.61 \mathrm{~m}$ wide, and $12.7 \mathrm{~mm}$ thick vertical wall made of plywood. Five full-scale flame spread experiments were conducted. The samples were exposed to a specified heat flux from a large-scale radiant panel. The following measurements were made: (1) rate of heat release, (2) total heat flux to the specimen surface, (3) surface temperature, and (4) propagation of the pyrolysis front. The full-scale test results demonstrated the sensitivity of the flame spread rate to the external heat flux.

Figure 3 shows a comparison of experimental and predicted heat release rates during upward flame spread over the vertical plywood surface for Test 1 [10]. In Figure 3, the agreement with experiment measurement is very good. Typical measured peak heat release rate results in this test series, along with the predicted peak heat release rate results and flame heat flux, are summarized in Table 1.

TABLE 1. Comparison of Experimental and Predicted Flame Heat Flux and Heat Release Rate Results

\begin{tabular}{||c|c|c|c|c|c|c|c||}
\hline $\begin{array}{c}\text { Test } \\
\text { number } \\
\text { and } \\
\text { plywood } \\
\text { type }\end{array}$ & $\begin{array}{c}\text { External } \\
\text { heat flux } \\
\text { applied } \\
\left(\mathrm{kW} / \mathrm{m}^{2}\right)\end{array}$ & $\begin{array}{c}\text { Modeled } \\
\text { flame } \\
\text { heat flux } \\
\left(\mathrm{kW} / \mathrm{m}^{2}\right)\end{array}$ & $\begin{array}{c}\text { Total } \\
\text { predicted } \\
\text { flame } \\
\text { heat flux } \\
\left(\mathrm{kW} / \mathrm{m}^{2}\right)\end{array}$ & $\begin{array}{c}\text { Total } \\
\text { measured } \\
\text { flame } \\
\text { heat flux } \\
\left(\mathrm{kW} / \mathrm{m}^{2}\right)\end{array}$ & $\begin{array}{c}\text { Initial } \\
\text { surface } \\
\text { temp } \\
\left({ }^{\circ} \mathrm{C}\right)\end{array}$ & $\begin{array}{c}\text { Measured } \\
\text { peak heat } \\
\text { release } \\
\text { rate } \\
(\mathrm{kW})\end{array}$ & $\begin{array}{c}\text { Predicted } \\
\text { peak heat } \\
\text { release } \\
\text { rate } \\
(\mathrm{kW})\end{array}$ \\
\hline \hline 1 GIS & 5.2 & 37 & 42.2 & $34-40$ & 160 & 118 & 114 \\
\hline 2 RG & 11 & 38 & 49 & $45-50$ & 250 & 250 & 136 \\
\hline 3 RG & 7.5 & 38 & 45.5 & $40-45$ & 205 & 130 & 124 \\
\hline 4 GIS & 4.8 & 33 & 37.8 & $33-38$ & 155 & 105 & 100 \\
\hline 5 GIS & 7 & 38 & 45 & $40-45$ & 200 & 175 & 123 \\
\hline
\end{tabular}




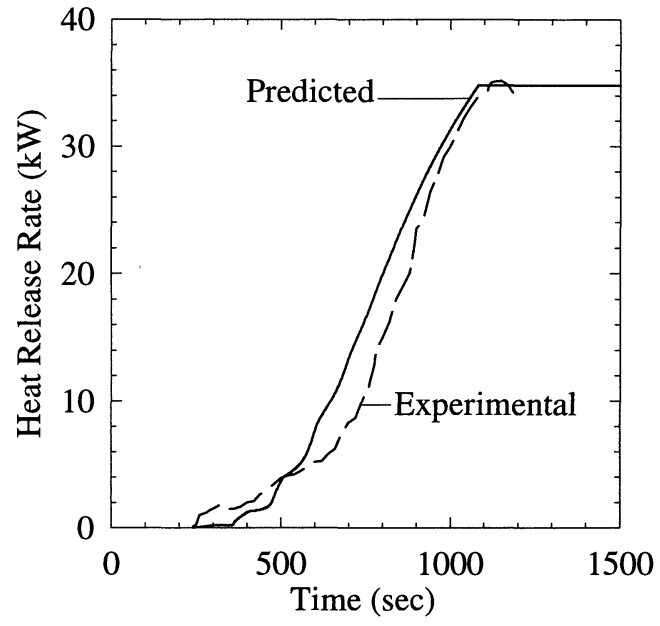

FIGURE 1. Comparison of heat release rate predictions for a $0.90 \mathrm{~m}$ x $0.20 \mathrm{~m}$ vertical PMMA surface with Wu et al., [9] data.

Model Input Data: $\mathrm{y}_{\mathrm{f}}=0.052 \mathrm{Q}^{2 / 3}, \mathrm{q}^{\prime \prime}=21 \mathrm{~kW} / \mathrm{m}^{2}, \mathrm{~T}_{\mathrm{ig}}=320^{\circ} \mathrm{C}, \mathrm{T}_{\mathrm{p}}=377^{\circ} \mathrm{C}, \mathrm{kpc}=0.60$ $\left(\mathrm{kW} / \mathrm{m}^{2} \mathrm{~K}\right)^{2} \mathrm{sec}, \Delta \mathrm{h}_{\mathrm{g}}=1600 \mathrm{~kJ} / \mathrm{kg}$

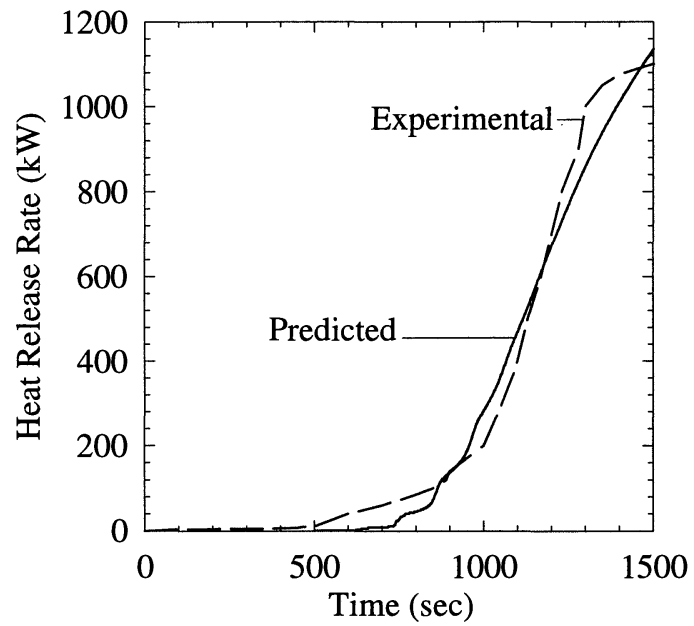

FIGURE 2. Comparison of heat release rate predictions for a $5.0 \mathrm{~m}$ x $0.58 \mathrm{~m}$ vertical PMMA surface with Wu et al., [9] data.

Model Input Data: $\mathrm{y}_{\mathrm{f}}=0.052 \mathrm{Q}^{2 / 3}, \mathrm{q}^{\prime \prime}=36 \mathrm{~kW} / \mathrm{m}^{2}, \mathrm{~T}_{\mathrm{ig}}=320^{\circ} \mathrm{C}, \mathrm{T}_{\mathrm{p}}=377^{\circ} \mathrm{C}$ $\mathrm{kpc}=0.60\left(\mathrm{~kW} / \mathrm{m}^{2} \mathrm{~K}\right)^{2} \mathrm{sec}, \Delta \mathrm{h}_{\mathrm{g}}=1600 \mathrm{~kJ} / \mathrm{kg}$ 


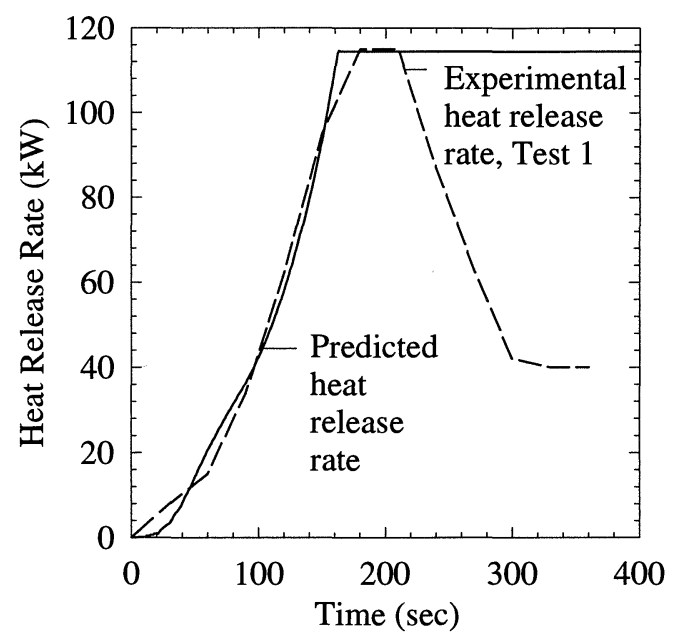

FIGURE 3. Comparison of heat release rate predictions for a $2.4 \mathrm{~m} \mathrm{x} 0.61 \mathrm{~m}$ vertical plywood surface with Delichatsios et al., [10] data.

Model Input Data: $\mathrm{y}_{\mathrm{f}}=0.052 \mathrm{Q}^{2 / 3}, \mathrm{q}^{\prime \prime}=37 \mathrm{~kW} / \mathrm{m}^{2}$, Imposed heat flux $=5.2 \mathrm{~kW} / \mathrm{m}^{2}, \mathrm{~T}_{\mathrm{ig}}=350$ ${ }^{\circ} \mathrm{C}, \mathrm{T}_{\mathrm{p}}=427{ }^{\circ} \mathrm{C}, \mathrm{k \rho c}=0.475\left(\mathrm{~kW} / \mathrm{m}^{2} \mathrm{~K}\right)^{2} \mathrm{sec}, \Delta \mathrm{h}_{\mathrm{g}}=6850 \mathrm{~kJ} / \mathrm{kg}$

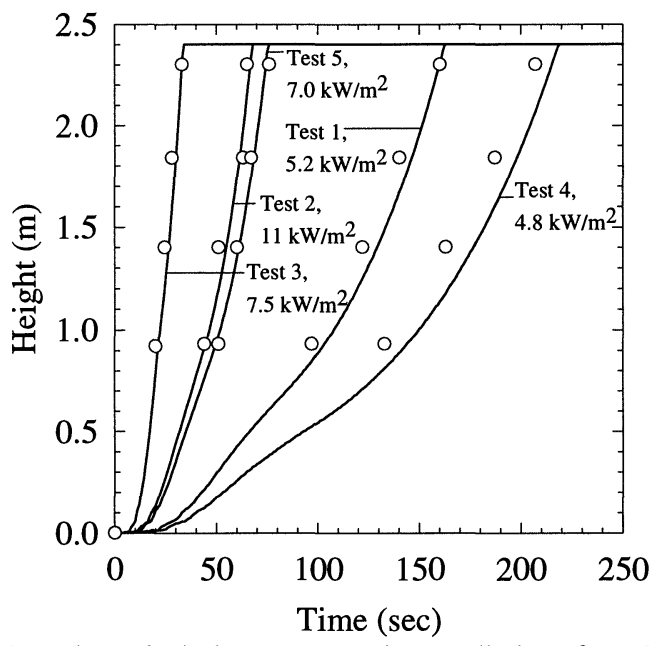

FIGURE 4. Comparsion of pyrolysis front propagation predictions for a $2.4 \mathrm{~m} \mathrm{x} 0.61 \mathrm{~m}$ vertical plywood surface with Delichatsios et al., [10] data.

Open Symbols: Experimental pyrolysis front propagation.

Solid Lines: Predicted pyrolysis front propagation: $\mathrm{y}_{\mathrm{f}}=0.052 \mathrm{Q}^{2 / 3}$,

$\mathrm{T}_{\mathrm{ig}}=350^{\circ} \mathrm{C}, \mathrm{T}_{\mathrm{p}}=427^{\circ} \mathrm{C}, \mathrm{kpc}=0.475\left(\mathrm{~kW} / \mathrm{m}^{2} \mathrm{~K}\right)^{2} \mathrm{sec}, \Delta \mathrm{h}_{\mathrm{g}}=6850 \mathrm{~kJ} / \mathrm{kg}$ 
The predictions and experimental propagation of the pyrolysis front are shown in Figure 4. The experimental values were deduced by Delichatsios et al. [10] flame surface thermocouple measurements. There is a good agreement between predicted and measured propagation of the pyrolysis zone. Figure 5 shows the temperature rise history of the plywood specimen with a uniform external heat flux of $5.2 \mathrm{~kW} / \mathrm{m}^{2}$ over a period of 1200 seconds ( 20 minutes). The temperature rise and steady preheat temperature were well predicted by the model.

\section{Comparison of Predicted Results with Experimental Results for Vinyl-Ester/Glass Composite}

Ohlemiller and Cleary [11] have examined the mechanisms and rate of upward flame spread along vertical panel of vinyl-ester/glass composite material $0.95 \mathrm{~cm}(0.37$ in. $)$ thick, $0.38 \mathrm{~m}$ $(1.25 \mathrm{ft})$ wide, and $1.22 \mathrm{~m}(4.0 \mathrm{ft})$ tall. The samples were exposed to a uniform external radiant heat flux ranging from $2.5 \mathrm{~kW} / \mathrm{m}^{2}$ to $11.5 \mathrm{~kW} / \mathrm{m}^{2}$. The samples were ignited with the equivalent of a $17 \mathrm{~kW} / \mathrm{m}$ line burner. Figure 6 compares the measured and predicted pyrolysis height versus the time for external radiant heat flux exposure of $2.5 \mathrm{~kW} / \mathrm{m}^{2}$ and $11.5 \mathrm{~kW} / \mathrm{m}^{2}$. In addition, the predicted pyrolysis front for no external radiant heat flux is shown. The predicted pyrolysis heights using $2.5 \mathrm{~kW} / \mathrm{m}^{2}$ radiant heat flux overestimate the experimental data. The predicted pyrolysis front location for the $11.5 \mathrm{~kW} / \mathrm{m}^{2}$ radiant heat flux produces results in better agreement with the experimental data of Ohlemiller and Cleary [11].

\section{CONCLUSIONS}

A computer model has been developed that successfully addressed upward fire growth on vertical surfaces. The agreement with experimental results is good. Assumptions have been made based on the limited information for flame heat transfer rates to cause burning and spread, and more complete experimental results are needed. Small variation in the ignition and flame spread properties can have a significant effect on fire growth. Therefore, material properties need to be accurately determine to predict the flame spread characteristics of the material. Despite the sensitivity of the model to many input parameters, the model demonstrated good results over a range of experimental conditions.

The predicted heat release rate of PMMA in both small- and full-scale scenario are in good agreement with data using flame height correlations presented by Delichatsios [3]. Approximate wall heat flux profile have been developed based on the steady-state experimental data available in the literature [2]. There is considerable scatter and/or uncertainty in the data above the pyrolysis zone for burning wall material. Additional work is required to improve correlations of heat fluxes.

It is the intent of this work to present a simple flame spread model that integrates many of the features and capabilities of those described and that requires a minimum of input data and accurately predicts the fire growth along vertical walls subject to ignition sources. Ultimately, the model will be generalized so that two- and three-dimensional geometries may be modeled. The ultimate goal of these modeling efforts is to predict and evaluate the fire performance of U.S. Navy materials, products, and assemblies and to provide a link between small-scale ignition and heat release rate measurements in the cone calorimeter with the full-scale fire performance to ensure an environment safe from destructive fires. 


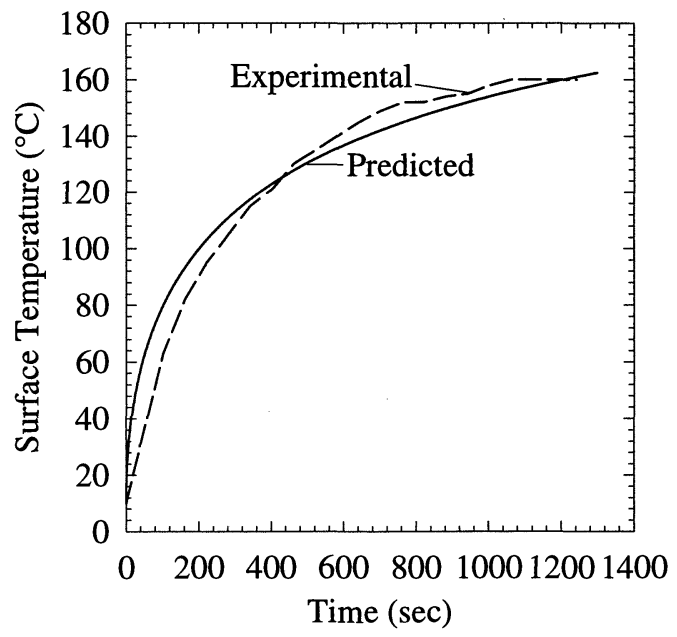

FIGURE 5. Comparison of preheating temperature prediction for a $2.4 \mathrm{~m} \mathrm{x} 0.61 \mathrm{~m}$ vertical plywood surface with Delichatsios et al., [10] data.

Model Input Data: Imposed heat flux $=5.2 \mathrm{~kW} / \mathrm{m}^{2}, \mathrm{kpc}=0.475\left(\mathrm{~kW} / \mathrm{m}^{2} \mathrm{~K}\right)^{2} \mathrm{sec}$.

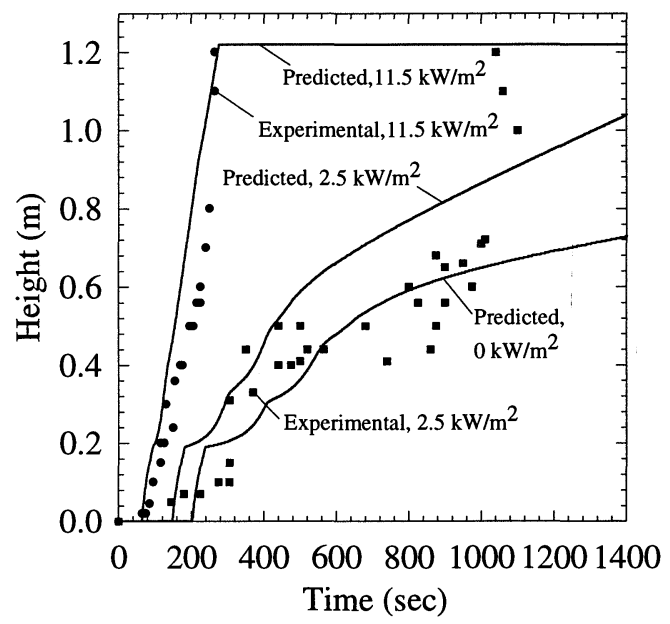

FIGURE 6. Comparison of pyrolysis front propagation prediction for a $1.22 \mathrm{~m} \mathrm{x} 0.38 \mathrm{~m}$ vertical vinyl ester panel with Ohlemiller and Cleary [11] data.

Solid Lines: Predicted pyrolysis front propagation $\mathrm{y}_{\mathrm{f}}=0.052 \mathrm{Q}^{2 / 3}, \mathrm{q}^{\prime \prime}=25 \mathrm{~kW} / \mathrm{m}^{2}$, $\mathrm{T}_{\mathrm{ig}}=377^{\circ} \mathrm{C}, \mathrm{T}_{\mathrm{p}}=427^{\circ} \mathrm{C}, \mathrm{kpc}=0.49\left(\mathrm{~kW} / \mathrm{m}^{2} \mathrm{~K}\right)^{2} \mathrm{sec}, \Delta \mathrm{h}_{\mathrm{g}}=1550 \mathrm{~kJ} / \mathrm{kg}$ 


\section{REFERENCES}

1. Williams, F.W., and Beyler, C.L., "Passive Fire Protection (PFP) Modeling Literature Review," NRL Letter Report Serial 6180/0221A, Naval Research Laboratory, Washington, DC, 13 July 1994.

2. Quintiere, J.G., and Cleary, T.G., "Heat Flux from Flames to Vertical Surfaces," Fire Technology, 30 (2), 1994, pp. 209-231.

3. Delichatsios, M.A., "Flame Heights in Turbulent Wall Fires with Significant Flame Radiation," Combustion Science and Technology, 39, 1984, pp. 195-214.

4. Tu, K-M., and Quintiere, J.G., "Wall Flame Heights with External Radiation," Fire Technology, 27 (3), August 1991, pp. 195-203.

5. Tewarson, A., "Generation of Heat and Chemical Compounds in Fires," The SFPE Handbook of Fire Protection Engineering, DiNenno, Editor, Second Edition, National Fire Protection Association, Quincy, MA, 1995.

6. Quintiere, J.G., "The Application of Flame Spread Theory to Predict Material Performance," Journal of Research of the National Bureau of Standards, 93 (1), January/February 1988, pp. 61-70.

7. $\quad$ Eckert, E.R., and Drake, R.M., "Analysis of Heat and Mass Transfer," Chapter 4, in Unsteady Heat Conduction, McGraw-Hill Book Company, 1972, pp. 138-221.

8. Williams, F.W., Beyler, C.L., Hunt, S.P., and Iqbal, N., "Upward Flame Spread on Vertical Surfaces," NRL/MR/6180--97-7908, Naval Research Laboratory, Washington, DC, Janaury 13, 1997.

9. Wu, P.-K., Delichatsios, M.M., and de Ris, J., "Upward Fire Spread over PMMA Walls - A Model/Experiment Comparison," 1993 Annual Conference on Fire Research: Book of Abstracts, NISTIR 5280, U.S. National Institute of Standards and Technology, Gaithersburg, Maryland, 1993, pp. 7-10.

10. Delichatsios, M.M., Wu, P.-K., Delichatsios, M.A., Lougheed, G.H., Crampton, G. P., Qian, C., Ishida, H., and Saito, K., "Effects of External Radiant Heat Flux on Upward Fire Spread: Measurements on Plywood and Numerical Predications," Fire Safety Science-Proceeding of the Fourth International Symposium, International Association of Fire Safety Science, Kashiwagi, Editor, 1994, pp. 421-432.

11. Ohlemiller, T.J., and Cleary, T.G., "Upward Flame Spread on Composite Material," ASC Symposium Series 599, Fire and Polymers II, Nelson, Editor, American Chemical Society, Washington, D.C., 1995, pp. 422-434. 